\title{
Mikroplastik pada Ikan Kembung (Rastrelliger sp.) dan Ikan Selar (Selaroides eptolepis) di TPI Tambak Lorok Semarang dan TPI Tawang Rowosari Kendal
}

\author{
Juwita Lesly Senduk, Jusup Suprijanto*, Ali Ridlo \\ Departemen Studi Ilmu Kelautan, Fakultas Perikanan dan Ilmu Kelautan, Universitas Diponegoro \\ Kampus Tembalang, Semarang Kode Pos 50275 \\ Email: jusup.suprijanto@yahoo.co.id
}

\begin{abstract}
Abstrak
Mikroplastik merupakan partikel plastik yang berukuran $\leq 5 \mathrm{~mm}$. Ukurannya yang kecil menyebabkannya dapat tertransportasikan ke seluruh tempat dan biota termasuk ikan. Ikan pelagis jenis ikan kembung dan ikan selar merupakan salah satu biota laut bernilai ekonomis tinggi dan banyak dikonsumsi masyarakat. Penelitian ini bertujuan untuk mengetahui kandungan mikroplastik pada ikan kembung dan ikan selar. Metode penelitian yang digunakan adalah deskriptif kualitatif. Sampel ikan kembung diambil di TPI Tambak Lorok Semarang, sedangkan ikan selar diambil dari TPI Tawang Rowosari Kendal. Penelitian ini dilakukan pada bulan Juni-Desember 2020. Tahapan penelitian yang dilakukan yaitu dimulai dengan pengambilan sampel, pengukuran sampel, pembedahan sampel, pelarutan sampel, pemisahan partikel mikroplastik, penyaringan partikel, dan identifikasi langsung secara visual menggunakan mikroskop. Hasil penelitian menunjukkan bahwa terdapat mikroplastik pada ikan selar dan kembung di TPI Semarang dan Kendal. Mikroplastik paling banyak dengan rerata 25,2 partikel pada insang dan 19,1 partikel pada pencernaan ditemukan pada ikan kembung di TPI Tambak Lorok, pada ikan selar (Selaroides leptolepis) ditemukan rerata 10,1 partikel pada insang dan 8,4 partikel pada pencernaan. Hasil yang didapatkan ditemukan bentuk fiber, fragmen, pelet, dan film, dengan warna yang beragam yaitu hitam, coklat, biru, putih, merah, transparan, dan kuning.
\end{abstract}

Kata kunci : Mikroplastik, Ikan, TPI, Semarang, Kendal

\section{Abstract \\ Microplastic content of Mackerel (Rastrelliger sp.) and Selar Fish (Selaroides leptolepis) at TPI Tambak Lorok Semarang and TPI Tawang Rowosari Kendal}

Microplastics are plastic particles with a size of $5 \mathrm{~mm}$. Its small size causes it easy to be transported to all places, including fish. Pelagic fish species of mackerel and selar fish are one of the marine biota that are economically feasible and widely consumed by the public. This study aims to determine the content of microplastics in mackerel and selar fish. The research method used is descriptive qualitative. Mackerel fish samples were taken at TPI Tambak Lorok Semarang, while selar fish were taken from TPI Tawang Rowosari Kendal. This research was conducted in June - December 2020. The stages of the research carried out were starting with sampling, measuring samples, separating samples, separating microplastic particles, evaluating particles, and directly using a microscope. The results showed that there were microplastics in selar and mackerel in TPI Semarang and Kendal. The most microplastics with an average of 25.2 particles in the gills and 19.1 particles in the digestion were found in mackerel at TPI Tambak Lorok, in selar fish (Selaroides leptolepis) an average of 10.1 particles were found in the gills and 8.4 particles in digestion. The results obtained were found in the form of fibers, fragments, pellets, and films, with various colors, namely black, brown, blue, white, red, transparent, and yellow.

Keywords : Microplastic, Fish, TPI, Semarang, Kendal

\section{PENDAHULUAN}

Sampah menjadi permasalahan bagi manusia dan lingkungan (Wahyuhastuti et al., 2017). Sampah dapat menimbulkan pencemaran pada wilayah perairan termasuk perairan Semarang dan Kendal. Salah satu jenis sampah yang ditemukan di perairan adalah sampah plastik. Sampah plastik yang masuk ke laut semakin lama 
akan terfragmentasi menjadi partikel yang lebih kecil, yaitu mikroplastik (Mulu et al., 2020). Mikroplastik merupakan potongan plastik yang berukuran <5 mm. Mikroplastik menurut bentuknya yaitu film, fragmen, fiber, dan pellet (Yona et al., 2020). Mikroplastik juga dibagi menjadi mikroplastik primer dan sekunder. Mikroplastik primer berasal dari bahan mentah untuk produk plastik atau berasal dari produk kosmetik. Mikroplastik sekunder merupakan mikroplastik yang terbentuk dari proses degradasi dari plastik yang berukuran besar (Wagner et al., 2014).

Mikroplastik dapat memeberikan bahaya yang besar bagi organisme laut, baik organisme yang berada pada tingkat trofik yang rendah seperti plankton, organisme filter feeder, dan organisme pada tingkat trofik yang lebih tinggi (Joesidawati, 2018). Mikroplastik di lingkungan laut dapat menggangu kehidupan laut termasuk ikan pelagis seperti ikan selar dan ikan kembung. Hal ini dikarenakan mikroplastik dapat tertelan oleh biota-biota tersebut pada saat mencari makan baik secara sengaja ataupun tidak dikarenakan bentuk makanannya yang sama atau dikarenakan mangsanya sudah terkontaminasi mikroplastik (Neves et al., 2015).

Beberapa penelitian terkait mikroplastik dalam ikan telah dilakukan di beberapa perairan Indonesia. Jenis mikroplastik fiber dan film ditemukan pada saluran pencernaan ikan lemuru protolan (Sardinella lemuru) (Yudhantari et al., 2019), jenis mikroplastik fiber, film, dan fragmen juga ditemukan pada ikan layur (Trichiurus lepturus), ikan layang (Decapterus russelli), ikan lemuru (Sardinella lemuru), dan ikan kembung (Rastrelliger kanagurta) (Sarasita et al., 2020). Ikan-ikan tersebut merupakan hasil tangkapan dari Selat Bali. Jenis mikroplastik fiber ditemukan pada pada 12 ikan karang yang berada di pulaupulau terkecil Papua yaitu Pulau Liki, Befondi dan Miossu yang kaya akan potensi ikan karang (Yona et al., 2020). Hasil penelitian lain juga ditemukan mikroplastik jenis film, fiber, pellet, dan granule pada sejumlah 13 spesies ikan dari 11 famili dari kelas Actynopterygii di dasar Laut Cina Selatan telah terkontaminasi mikroplastik yang ditemukan di perut dan ususnya. Beberapa jenis ikan tersebut adalah ikan ekonomis yang dijual sebagai makanan laut yaitu Rexea solandri, Synagrops japonicus dan Chlorophthalmus albatrossis (Zhu et al., 2019).
Ikan Selar dan Ikan Kembung merupakan ikan ekonomis penting yang banyak digemari masyarakat untuk dikonsumsi masyarakat dan berada di hampir seluruh perairan Indonesia. Ikan selar dan ikan kembung hidup pada lapisan permukaan sampai dengan kolom air. Ikan selar termasuk dalam ikan karnivora yang aktif di malam hari. Ikan ini memakan larva-larva ikan seperti dari family Cephalopoda, Balastidae, dan Serranidae (Chodrijah dan Faizah, 2018). Ikan Kembung memiliki kebiasaan memakan plankton besar atau kasar, copepoda dan crustacea (Utami et al., 2014). Organ pada ikan yang dapat terpapar mikroplastik adalah insang, saluran pencernaan serta lambung.

Penelitian sebelumnya telah ditemukan mikroplastik pada perairan muara sungai Kendal dan pada sedimen pada Perairan Laut Semarang (Hanif et al, 2021 dan Laila et al., 2020). Berdasarkan data kementrian perindustrian tahun 2020 terdapat beberapa pabrik industri di sekitar Tanjung Mas Semarang yang memproduksi botol plastik, kantong plastik, dan mebel plastik. Tambak Lorok merupakan wilayah pesisir dan tidak terlalu jauh dari pusat kota (Satker PKP Jawa Tengah, 2017). Tambak Lorok memiliki potensi yang besar dalam sektor perikanan maupun non perikanan (Kartikaningtyas et al., 2018). TPI Tawang Rowosari berada di pesisir Kendal. Perikanan yang ada di TPI Tawang Rowosari diambil dari kapal yang mendarat di TPI. Perairan di Kabupaten Kendal menjadi wilayah penyebaran ikan pelagis dan demersal yang cukup berpotensi di wilayah perairan Utara Jawa Tengah (Rahman et al., 2013). Sampel ini diharapkan dapat mewakili dari perairan Semarang dan Kendal.

Ditemukannya mikroplastik di perairan laut menjadikan penelitian mengenai mikroplastik pada ikan menjadi salah satu yang penting dilakukan. Penelitian mengenai mikroplastik perlu dilakukan untuk mengetahui sejauh mana mikroplastik mencemari suatu perairan dan apakah mikroplastik tersebut telah masuk ke dalam organ organisme di perairan tersebut. Berdasarkan pemaparan tersebut, maka akan dilakukan penelitian kandungan mikroplastik pada ikan kembung (Rastrelliger $\mathrm{sp}$.) dan ikan selar (Selaroides leptolepis) di TPI Tambak Lorok Semarang dan TPI Tawang Rowosari Kendal.

\section{MATERI DAN METODE}

Materi dalam penelitian ini adalah ikan pelagis jenis ikan kembung dari TPI Tambak 
Lorok Semarang dan ikan selar dari TPI Tawang Rowosari Kendal, yang diambil pada pada tanggal 10 Juli, 24 Juli, dan 10 Agustus. Ikan kembung dan ikan selar dipilih karena keberadaannya secara rutin dapat ditemukan. Sampel ikan selar dan kembung diambil sebanyak $1,5 \mathrm{~kg}$ secara acak. Sampel ikan kembung yang digunakan diambil di TPI Tambak Lorok, Semarang dan sampel ikan selar di TPI Tawang Rowosari, Kendal yang merupakan hasil tangkapan one day fishing. Sistem One day fishing ini merupakan penangkapan yang jangkauan wilayah penangkapannya terbatas hanya 6 mil laut dari garis pantai.

\section{Pengukuran Sampel Ikan}

Sampel Ikan diukur panjang, lebar, dan tingginya menggunakan penggaris dan diukur berat total, serta berat per organnya yaitu berat pencernaan, dan berat insang menggunakan timbangan digital. Ikan diukur secara horizontal dari ujung rahang sampai ujung ekor. Lebar ikan diukur secara vertikal pada bagian tengah badan. Tinggi ikan diukur sesuai ketebalan ikan dari sirip atas sampai sirip bawah (Islamadina et al., 2018).

\section{Pembedahan Sampel}

Sampel ikan yang telah selesai diukur masing-masing dibedah dan diambil saluran pencernaan dan insangnya. Ikan dibedah dengan menggunting dari anus ke arah dorsal sampai gurat sisi/linea lateralis, alu ke arah anterior sampai belakang kepala dan ke arah bawah hingga ke bagian dasar perut sampai isi perut ikan terlihat. Ikan yang sudah terbedah kemudian diambil pencernaan dan insangnya. Ditimbang beratnya dan dimasukkan ke dalam plastik ziplock yang sudah diberi tagging.

\section{Pemisahan Mikroplastik dengan Partikel Lain}

Sampel pencernaan dan insang yang sudah dipisahkan lalu dilakukan perendaman menggunakan $\mathrm{KOH} 10 \%$ selama 24 jam untuk melarutkan sampel dan menghilangkan bahan organiknya. Larutan $\mathrm{ZnCl}_{2}$ ditambahkan dan dihomogenkan selama 1-2 menit kemudian didiamkan 24 jam. Lapisan di bagian atas yang berwarna bening diambil sebanyak $10 \mathrm{ml}$ untuk selanjutnya di vacuum pump dan kertas saring, lalu sampel dikeringkan. Selanjutnya, diidentifikasi secara visual menggunakan mikroskop perbesaran 100x untuk diamati bentuk, warna, ukuran, dan dihitung jumlahnya menggunakan mikroskop binokuler Olympus CX21 Binokuler dibantu menggunakan software ScopeImage (Karami et al., 2017).

\section{HASIL DAN PEMBAHASAN}

Mikroplastik yang ditemukan pada pelagis pencernaan dan insang ikan pelagis jenis ikan kembung di TPI Tambak Lorok Semarang dan ikan selar dan TPI Tawang Rowosari Kendal yaitu mikroplastik bentuk fragmen, fiber, pelet, dan film. Mikroplastik bentuk fragmen merupakan partikel plastik umumnya memiliki bentuk tidak beraturan dengan ujung-ujung yang tajam. Fiber dapat diidentifikasi dengan melihat bentuknya yang cenderung panjang dengan ketebalan yang hampir sama. Pelet merupakan partikel plastik yang berbentuk bulat. Film merupakan potongan plastik yang memiliki lapisan sangat tipis berbentuk lembaran dengan densitas yang rendah (Yona et al., 2020).

Analisis mikroplastik pada ikan kembung dan selar dilakukan pada dua bagian ikan, yaitu bagian pencernaan dan insang. Hal ini sesuai dengan pernyataan bahwa pada ikan, organ tubuh yang dapat terakumulasi mikroplastik diantaranya adalah insang, saluran pencernaan, dan lambung (Murphy et al., 2017 dan Baalkhuyur et al., 2018).

Mikroplastik pada insang di TPI Semarang dan Kendal ditemukan lebih tinggi daripada bagian pencernaan. Hal ini diduga dipengaruhi oleh adanya perbedaan fungsi organ. Insang berfungsi sebagai tempat keluar masuknya air dalam proses pernafasan (Su et al., 2019). Fungsi insang sebagai tempat keluar masuknya air diduga menyebabkan mikroplastik bisa masuk ke dalam insang. Tidak mengurangi kemungkinan pula terdapat beberapa mikroplastik yang tersangkut sehingga menempel pada insang. Bisa jadi hal ini menyebabkan banyak mikroplastik yang menempel pada insang ikan, sedangkan pencernaan merupakan tempat proses pencernaan makanan ikan. Hal ini menjadikannya sebagai tempat terakumulasinya mikroplastik (Murphy et al., 2017 dan Baalkhuyur et al., 2018). Perbedaan jumlah mikroplastik yang ditemukan pada pencernaan ikan diduga karena adanya perbedaan ukuran saluran pencernaan. Mikroplastik yang memiliki ukuran kecil dapat keluar melalui feses, namun apabila ukurannya besar maka ia akan terperangkap di pencernaan. Mikroplastik ini dapat masuk ke pencernaan ikan 
melalui sistem rantai makanan. Mikroplastik dapat tertelan oleh ikan secara sengaja maupun tidak sengaja pada prosesnya mencari makan karena bentuknya hampir sama dengan jenis makanannya atau karena mangsanya telah terkontaminasi mikroplastik (Neves et al., 2015).

Mikroplastik yang ditemukan pada ikan kembung yang paling dominan adalah berbentuk pellet, sedangkan pada ikan selar berbentuk mikroplastik fiber. Mikroplastik bentuk fiber yang ditemukan diduga bersumber dari kegiatan perikanan yang berasal dari alat tangkap seperti pancing, jaring dan jala yang terurai. Selain itu, tali tambang yang berada di kapal juga berpotensi terfragmentasi. Fiber juga dapat berasal dari limbah rumah tangga berupa hasil pencucian kain yang dapat melepaskan sisa benang, serta melalui tali plastik yang terpecahkan. Mikroplastik bentuk fiber termasuk jenis plastik yang melimpah di perairan sehingga ia berpotensi tertelan ikan (Yona et al., 2020). Pelet dapat berasal dari bahan baku kegiatan industri, bahan toiletries, scrub, sabun, dan pembersih muka. Mikroplastik bentuk pelet diduga bersumber dari kegiatan domestik berupa limbah rumah tangga seperti air bekas cucian yang mengandung pelet serta dapat berasal dari bahan baku industri (Hiwari et al., 2019). Mikroplastik bentuk fragmen ini dapat berasal dari potongan plastik yang berasal dari botol minum, kantong plastik, pipa paralon, kepingan galon, dan kemasan makanan lainnya. Mikroplastik bentuk Film berasal dari kantong plastik dan kemasan makanan yang cenderung berwarna transparan.

Jumlah mikroplastik yang ditemukan pada ikan kembung (1.065 partikel) ditemukan lebih banyak dibandingkan pada ikan selar (444 partikel). Mikroplastik yang dominan pada ikan kembung adalah bentuk pelet (456 partikel), diikuti fragmen (324 partikel), fiber (280 partikel), dan film (5 partikel), sedangkan pada ikan selar,

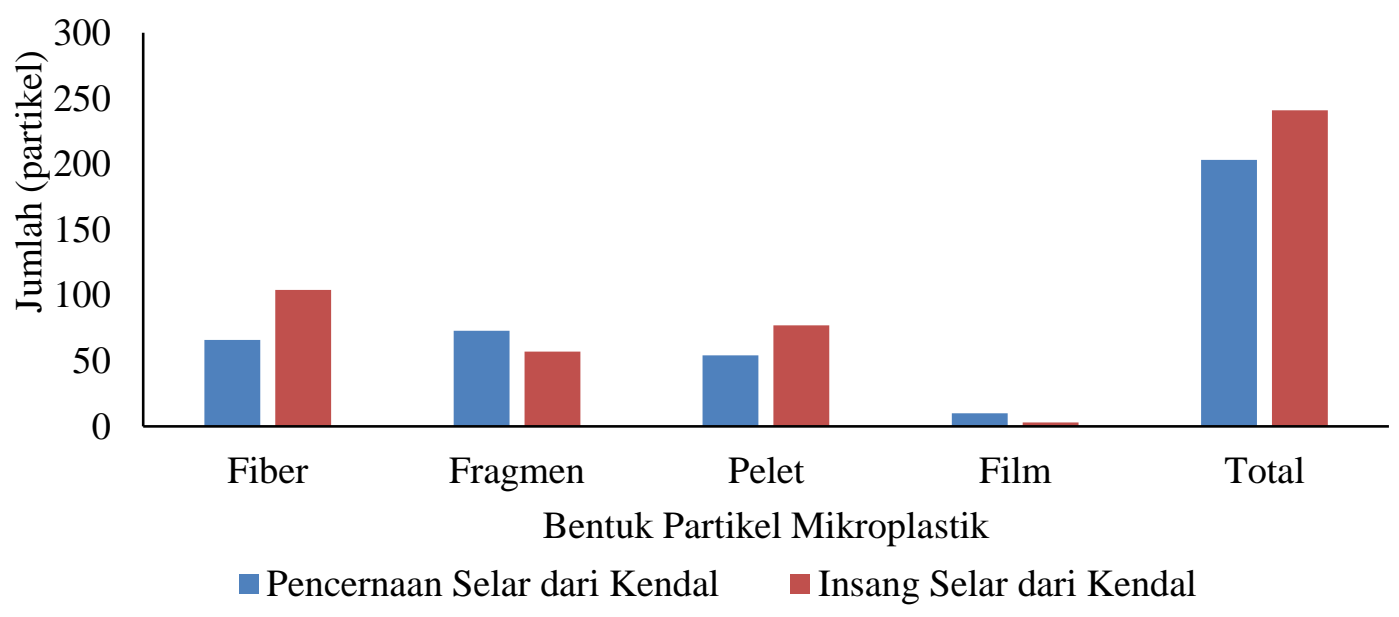

Gambar 1. Jumlah Partikel Mikroplastik pada Pencernaan dan Insang Ikan Selar dari Kendal

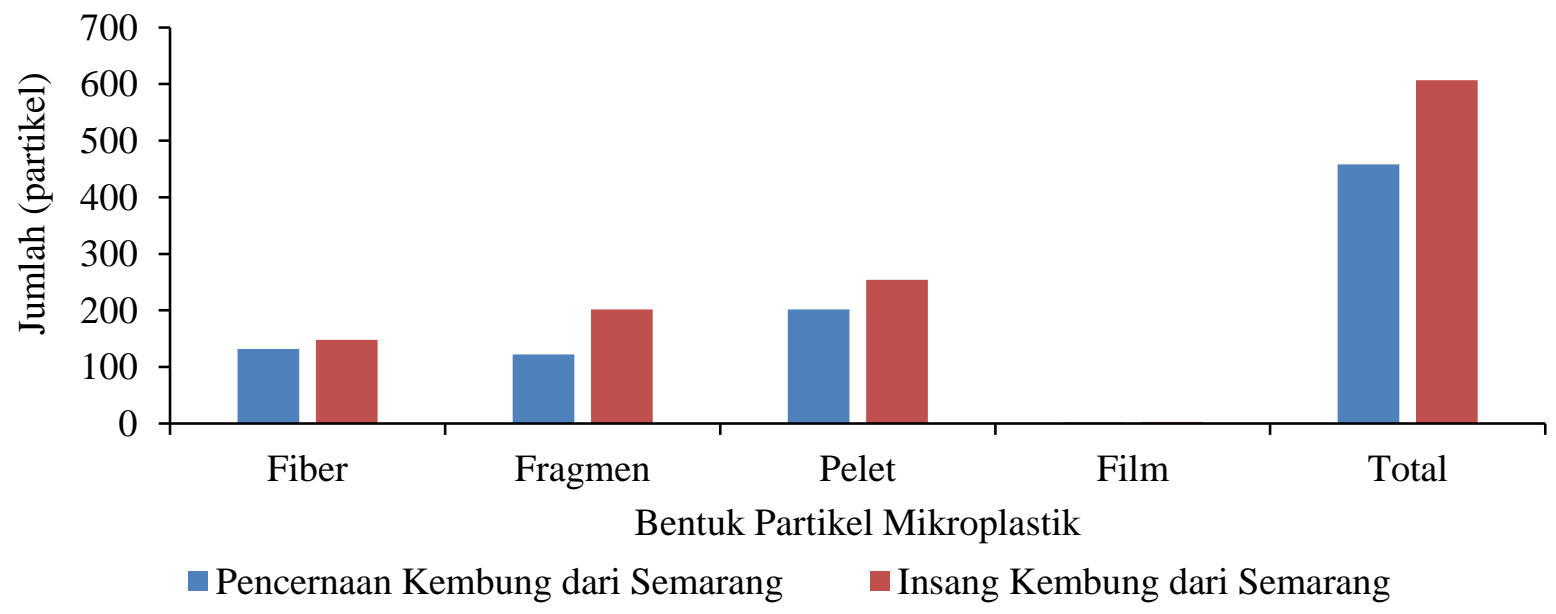

Gambar 2. Jumlah Partikel Mikroplastik pada Pencernaan dan Insang Ikan Kembung dari Semarang 


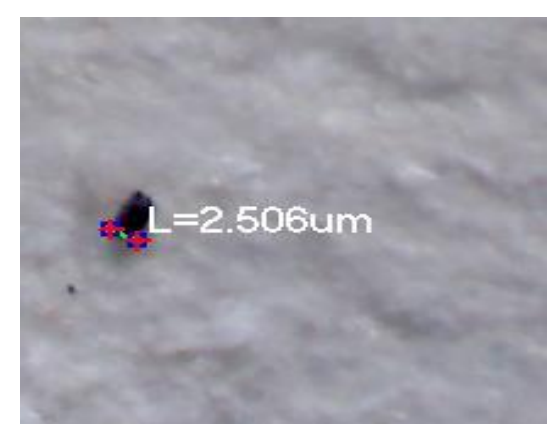

Fragmen

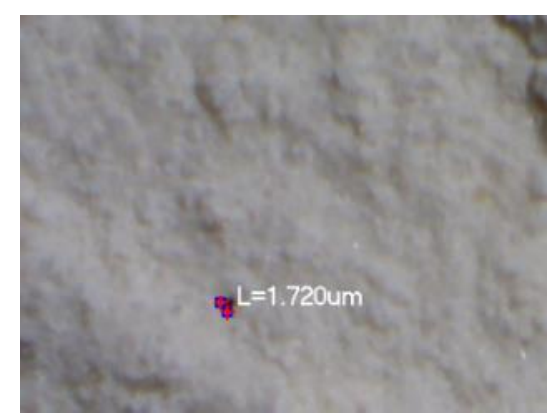

Pelet

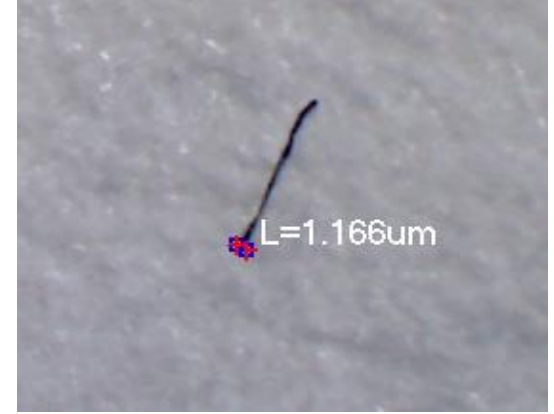

Fiber

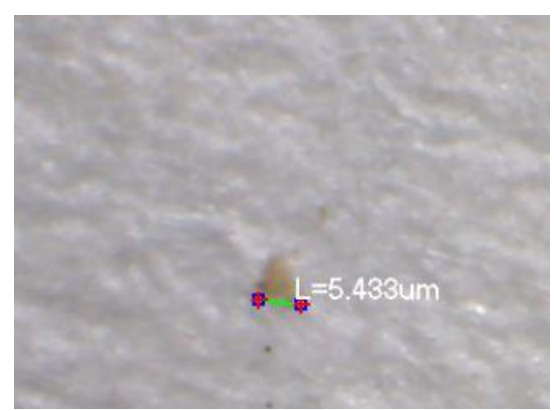

Film

Gambar 3. Bentuk Partikel Mikroplastik yang ditemukan di Ikan Selar dari Kendal

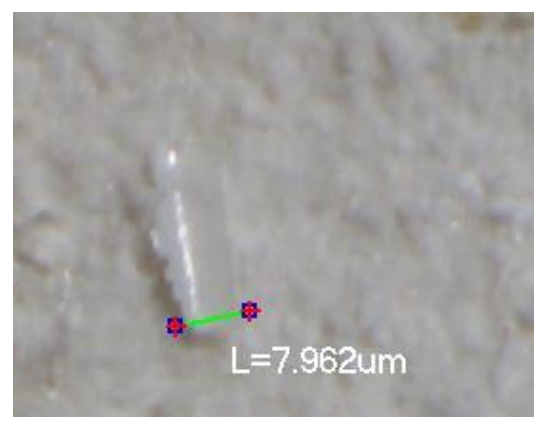

Fragmen

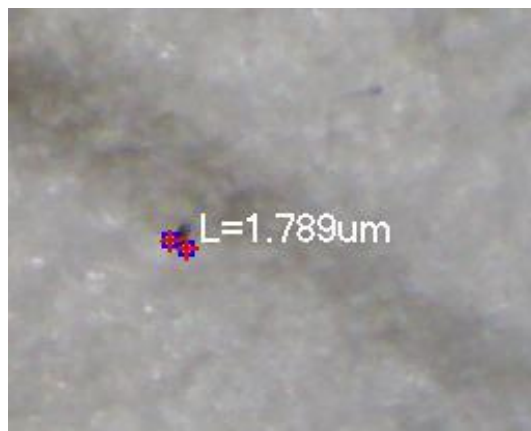

Pelet

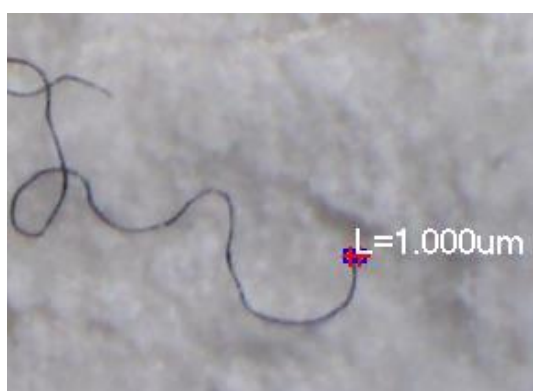

Fiber

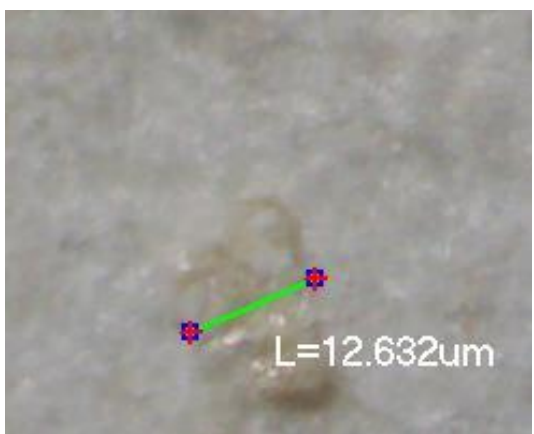

Film

Gambar 4. Bentuk Partikel Mikroplastik yang ditemukan di Ikan Kembung dari Semarang

mikroplastik terbanyak adalah bentuk fiber (170 partikel), diikuti pelet (131 partikel), fragmen (130 partikel), dan film (13 partikel). Jumlah mikroplastik yang paling banyak ditemukan pada 
ikan kembung di TPI Tambak Lorok Semarang diduga karena lokasi penangkapan ikan ini telah tercemar mikroplastik.

Partikel mikroplastik memiliki beragam ukuran. Perbedaan ukuran yang terjadi pada mikroplastik dipengaruhi oleh waktu mikroplastik mengalami proses fragmentasi di perairan, semakin kecil ukuran mikroplastik berarti semakin lama waktu yang dibutuhkan untuk terfargmentasi di perairan. Ukuran mikroplastik juga dipengaruhi oleh radiasi sinar UV dan gelombang laut (Claessense et al., 2011). Partikel mikroplastik yang berukuran kecil diduga menyebabkannya mudah masuk ke dalam ikan baik secara sengaja ataupun tidak sengaja dalam prosesnya mencari makan.

Warna mikroplastik yang ditemukan pada ikan kembung dan selar yaitu hitam, coklat, biru, putih, merah, transparan, dan kuning. Warna yang mendominasi yaitu warna hitam. Warna hitam banyak ditemukan bisa dikarenakan memang dari sumbernya berwarna hitam. Warna pada mikroplastik juga dapat menjadi indikasi partikel organik lain yang terserap dalam mikroplastik atau memang warna asli dari sumber plastiknya. Perbedaan warna mikroplastik juga dipengaruhi oleh lamanya terpapar sinar matahari sehingga lama kelamaan akan mengalami oksidasi yang

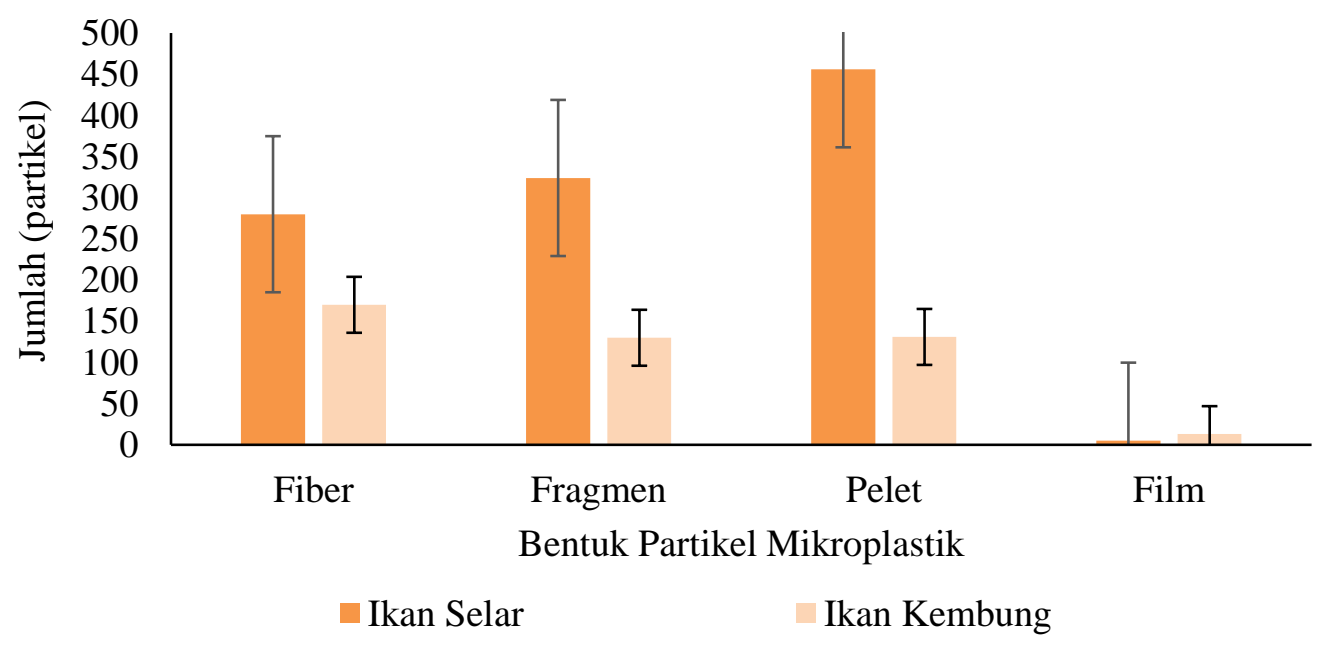

Gambar 5. Jumlah Mikroplastik pada Insang dan Pencernaan Ikan Kembung dari Semarang dan Ikan Selar dari Kendal Berdasarkan Bentuk
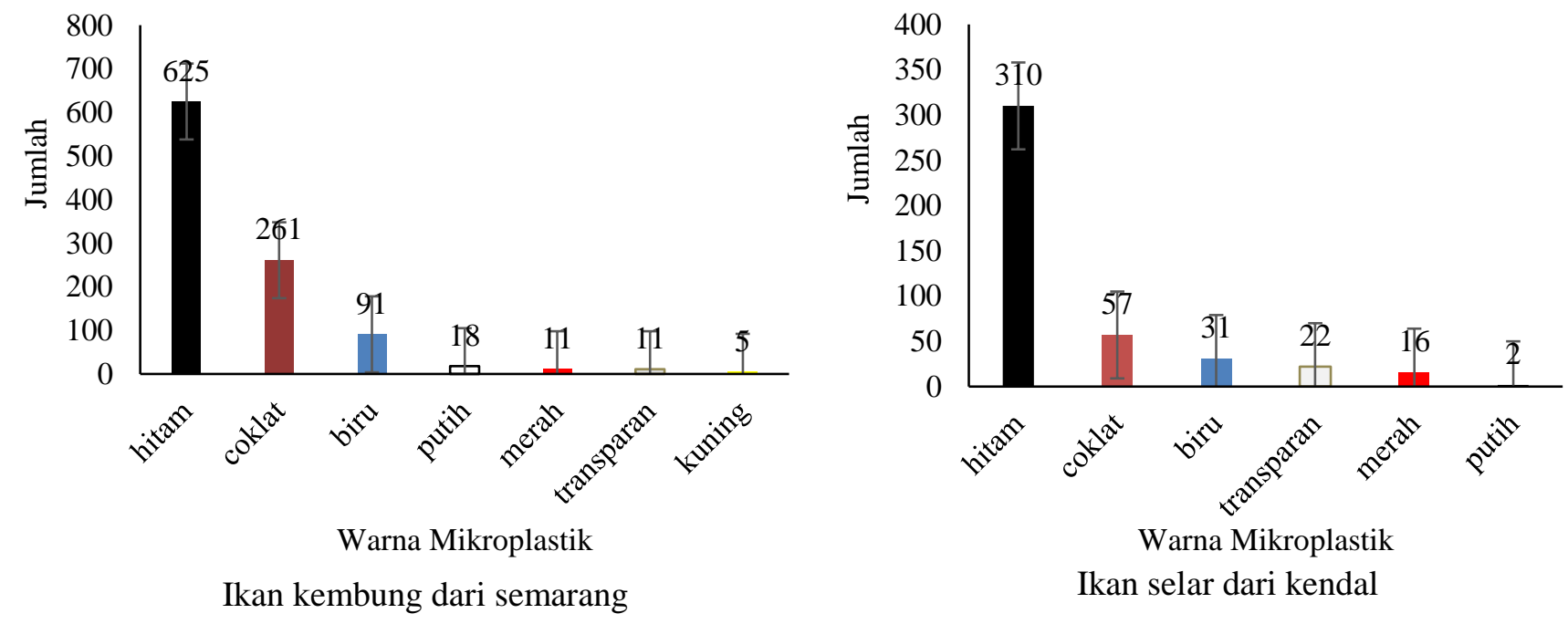

Gambar 6. Warna mikroplastik yang ditemukan dalam ikan 
menyebabkan mikroplastik berubah warna (Browne, 2015). Jumlah mikroplastik yang ditemukan dalam cenderung tidak ada hubungan antara ukuran/berat ikan dengan jumlah mikroplastik yang ditemukan.

Pada ikan kembung, ikan yang paling berat yaitu 73,57 g dengan jumlah mikroplastik 30 partikel, sedangkan ikan yang paling ringan yaitu 27,08 g dengan jumlah mikroplastik 49 partikel. Berat ikan 60,36 g memiliki jumlah partikel mikroplastik paling banyak yaitu 111 partikel, sedangkan pada berat $68,65 \mathrm{~g}$ memiliki partikel mikroplastik yang paling sedikit yaitu 15 partikel.

Tabel 1. Ukuran Biota dan Jumlah Mikroplastik

\begin{tabular}{ccc}
\hline Jenis ikan & $\begin{array}{c}\text { Berat } \\
\text { Ikan }(\mathrm{g})\end{array}$ & $\begin{array}{c}\text { Jumlah Mikroplastik } \\
\text { (Partikel) }\end{array}$ \\
\hline Ikan & 27,08 & 49 \\
Kembung & 32,46 & 42 \\
& 33,52 & 23 \\
& 40,29 & 55 \\
& 42,48 & 25 \\
& 42,66 & 32 \\
& 60,36 & 111 \\
& 68,65 & 15 \\
& 73,57 & 30 \\
\hline Ikan Selar & 12,9 & 8 \\
& 18,93 & 16 \\
& 23,82 & 7 \\
& 26,72 & 14 \\
& 29,13 & 16 \\
& 30,24 & 13 \\
& 33,81 & 2 \\
& 35,29 & 15 \\
& 37,46 & 6 \\
\hline
\end{tabular}

Pada ikan selar, ikan yang paling berat yaitu 37,46 $\mathrm{g}$ dengan jumlah mikroplastik 6 partikel, sedangkan ikan yang paling ringan yaitu $12,9 \mathrm{~g}$ dengan jumlah mikroplastik 8 partikel. Berat ikan $18,93 \mathrm{~g}$ dan $29,13 \mathrm{~g}$ memiliki partikel mikroplastik paling banyak yaitu 16 partikel, sedangkan pada berat ikan 33,81 g memiliki partikel yang paling sedikit yaitu 2 partikel. Pada hasil yang didapatkan, berat ikan tidak berpengaruh pada jumlah mikroplastik yang ada di dalam ikan.. Ikan yang memiliki berat yang lebih ringan belum tentu memiliki mikroplastik yang paling sedikit, begitu pula sebaliknya. Perbedaan jumlah partikel ikan kembung dan ikan selar bervariasi, dan apabila dilihat dari hasil yang ditemukan

mikroplastik yang ditemukan dapat dikarenakan tingkat pencemaran perairan yang berbeda, dapat pula dikarenakan berat mikroplastik sangat ringan, selain itu, dalam usahanya mencari makan ikan juga memiliki kemampuan yang berbeda, selain itu faktor lain yang dapat mempengaruhi umur hidup ikan, makanan ikan, mulut ikan, dan lokasi penangkapan ikan.

\section{KESIMPULAN}

Mikroplastik ditemukan pada kedua jenis ikan, didominasi bentuk pellet, diikuti fragmen, fiber, dan film. Warna mikroplastik yang dominan adalah hitam, diikuti coklat, biru, transparan, merah, putih, dan kuning. Tidak ada hubungan antara berat ikan dengan jumlah mikroplastik.

\section{UCAPAN TERIMA KASIH}

Riset ini dapat terselenggara berkat DANA SELAIN APBN DPA SUKPA Fakultas Perikanan dan Ilmu Kelautan Universitas Diponegoro, Tahun Anggaran 2020 sebagai Ketua Peneliti Dr.Ir. Jusup Suprijanto, DEA. Penulis sampaikan terimakasih untuk semua pihak yang telah membantu hingga terselesaikannya penelitian ini.

\section{DAFTAR PUSTAKA}

Baalkhuyur, F. M., E. J. A. B. Dohaish, M. E. A. Elhalwagy, N. M. Alikunhi, A. M. AlSuwailem, A. Rostad, D. J. Coker, M. L. Berumen, dan C. M. Duarte. 2018. Microplastic in the gastrointestinal tract of fishes along the Saudi Arabian Red Sea coast. Marine Pollution Bulletin. 131: 407415. doi: 10.1016/j.marpolbul.2018.04. 040.

Browne, M.A. 2015. Sources and Pathways of Microplastics to Habitats. Marine Anthropogenic Litter. Springer International Publishing. 229-244.

Chodrijah, U. \& Faizah, R. 2018. Biologi Reproduksi Selar Bentong (Selar Crumenophthalmus Bloch, 1793) di Perairan Kwandang, Gorontalo Utara. Bawal 10(3): 169-177.

Claessens, M., De Meester, S., Van Landuyt, L., De Clerck, K. \& Janssen, C.R., 2011. Occurence and Distribution of Microplastics 
in Marine Sedimens Along the Belgian coast. Marine Pollution Bulletin. 62(10): 21992204.

Hanif, H.K., Suprijanto, J. \& Praktikto, I. 2021. Identifikasi Mikroplastik di Muara Sungai Kendal, Kabupaten Kendal. Journal of Marine Research. 10(1):1-6.

Hiwari, H., Purba, N.P., Ihsan, Y.N., Yuliadi, L.P.S. \& Mulyani, P.G. 2019. Kondisi Sampah Mikroplastik di Permukaan Air Laut Sekitar Kupang dan Rote, Provinsi Nusa Tenggara Timur. Prosiding Seminar Nasional Masyarakat Biodiversitas Indonesia. 5 (2):165-171. doi: 10.13057/psn $\mathrm{mbi} / \mathrm{m} 050204$

Islamadina, R., Pramita, N., Arnia, F., Munadi, K. \& Iqbal, T.W.K.M. 2018. Pengukuran Badan Ikan Berupa Estimasi Panjang, Lebar, dan Tinggi Berdasarkan Visual Capture. Jurnal Nasional Teknik Elektro dan Teknologi Informasi. 7(1):57-63.

Joesidawati, M.I. 2018. Pencemaran Mikroplastik Di Sepanjang Pantai Kabupaten Tuban.

Karami, A., Golieskardi, A., Choo, C.K., Romano, N., Ho, Y.B. \& Salamatinia, B. 2017. A HighPerformance Protocol for Extraction of Microplastics in Fish. Science of the Total Environment, 578:485-494.

Kartikaningtyas, G.C., Bambang, A.N. \& Kurohman, F. 2018. Analisis Perbandingan Pendapatan Nelayan Arad, Gill Net dan Trammel Net di Tambak Lorok Kota Semarang. Journal of Fisheries Resources Utilization Management and Technology, 7(3):63-70.

Laila, Q.N., Purnomo, P.W. \& Jati, O.E. 2020. Kelimpahan Mikroplastik pada Sedimen di Desa Mangunharjo, Kecamatan Tugu, Kota Semarang. Jurnal Pasir Laut. 4(1):28-35.

Mulu, M., Hudin, R., Dasor, Y.W. \& Tarsan, V. 2020. Marine Debris dan Mikroplastik: Upaya Mencegah Bahaya dan Dampaknya di Tempode, Desa Salama, Kabupaten Manggarai, NTT. Jurnal Pengabdian Masyarakat. 3 (2): 79-84. doi: 10.36928/jrt. v3i2.404

Murphy, F., Russell, M., Ewins, C. \& Quinn, B. 2017. The uptake of macroplastic \& microplastic by demersal \& pelagic fish in the Northeast Atlantic around Scotland. Marine Pollution Bulletin. 122:353-359. doi: 10.1016/j.marpolbul.2017.06.073
Neves, D., Sobral, P., Ferreira, J.L. \& Pereira, T. 2015. Ingestion of microplastics by commercial fish off the Portuguese coast. Marine Pollution Bulletin. 101:119-126.

Rahman, D.R., Triarso, I. \& Asriyanto. 2013. Analisis Bioekonomi Ikan Pelagis pada Usaha Perikanan Tangkap di Pelabuhan Perikanan Pantai Tawang Kabupaten Kendal. Journal of Fisheries Resources Utilization Management and Technology. 2(1):1-10.

Satker PKP Jawa Tengah. 2017. Rencana Aksi Perbaikan Lingkungan (Neighborhood Upgrading Action Plan - NUAP) pada Program Neighborhood Upgrading and Shelter Project Phase-2 (NUSP-2). Kelurahan Tanjung Mas Tahun 2017. Semarang.

Su, L., Deng, H., Li, B., Chen, Q., Pettigrove, V., Wu, C. \& Shi, H. 2019. The occurrence of microplastic in specific organs in commercially caught fishes from coast and estuary area of east China. Journal Hazardous Material. 365:716-724.

Utami, M.N.F., Redjeki, S. \& Supriyantini, E. 2014. Komposisi Isi Lambung Ikan Kembung Lelaki (Rastrelliger Kanagurta) di Rembang. Journal of Marine Research. 2(3):99-106

Victoria, A.V. 2017. Kontaminasi Mikroplastik di Perairan Tawar. 1-10.

Wagner, M., Scherer, C., Alvarez-Muñoz, D., Brennholt, N., Bourrain, X., Buchinger, S., Fries, E., Grosbois, C., Klasmeier, J., Marti, T., Rodriguez-Mozaz, S., Urbatzka, R. Vethaak, A.D., Winther-Nielsen, M. \& Reifferscheid, G. 2014. Microplastics in Freshwater Ecosystems: What We Know and What We Need to Know. Environmental Sciences Europe. 26(1):1-9.

Wahyuhastuti, N., Indiworo, Rr.H.E. \& Burhanudin, A. 2017. IbM Pengolahan Sampah Plastik dalam Rangka Pemberdayaan Masyarakat Kelurahan Muktiharjo Kidul Semarang. Jati Emas (Jurnal Aplikasi Teknik dan Pengabdian Masyarakat). 1(2):82-85.

Yona, D., Maharani, M.D., Cordova, M.R., Elvania, Y. \& Dharmawan, I.W.E.. 2020 Analisis Mikroplastik di Insang dan Saluran Pencernaan Ikan Karang di Tiga Pulau Kecil dan Terluar Papua, Indonesia: Kajian Awal. Jurnal Ilmu dan Teknologi Kelautan Tropis. 12(2):497-507. doi: 10.29244/jitkt.v12i2.2597 